\title{
Strategic Trial to Find Aging Face Print
}

\author{
Khalifa E. Sharquie1 ${ }^{*}$, Sabeeh A. Al-Mashhadani', Ali Thamer Hameed ${ }^{2}$ \\ ${ }^{1}$ Department of Dermatology, College of Medicine, University of Baghdad, Iraqi and Arabic Board of \\ Dermatology, Baghdad, Iraq \\ ${ }^{2}$ Department of Dermatology and Venereology, Baghdad Teaching Hospital, Medical City, Baghdad, Iraq \\ Email: ${ }^{*}$ ksharquie@ymail.com
}

Received 24 November 2014; accepted 4 September 2015; published 7 September 2015

Copyright (C) 2015 by authors and Scientific Research Publishing Inc.

This work is licensed under the Creative Commons Attribution International License (CC BY). http://creativecommons.org/licenses/by/4.0/

(c) () Open Access

\section{Abstract}

Background: Wrinkling of face is a common feature of aging and each individual could have his own feature of disease. Objective: To categorize the wrinkles of each individual in order to find the characteristic picture of each individual aiming to find so called a print of aging. Patients and Methods: An observational study was done on 1011 cases their ages more than 30 years. 679 subjects $(67.2 \%)$ were males and $332(32.8 \%)$ were females. Their ages ranged between 30 - 86 years. Cases attended Department of Dermatology/Baghdad Teaching Hospital, Baghdad, Iraq in period from April 2012 to April 2013. The distribution and the types of wrinkling were mapped in all individuals. Regional variations including forehead, glabellae, periorbital, nasolabial, perioral and sides of the face were well studied. Results: Forehead horizontal pattern was presented in $860(85 \%)$ subjects, forehead vertical pattern in $84(8.3 \%)$, glabella horizontal pattern in $705(69.7 \%)$ and glabella vertical in $698(69 \%)$. Periorbital pattern was presented in $885(87.5 \%)$ subjects and nasolabial angle in $540(53.4 \%)$. Glabella vertical and horizontal patters were significantly more in males than females. Also, the males were significantly more affected by periorbital and nasolabial folds. Conclusion: Each individual or group of individual has characteristic morphological pattern of wrinkling that starts early in life and becomes mature often with time and this pattern might deserve the name of a print.

\section{Keywords}

Wrinkles, Mapping, Aging Face, Nasolabial Angle

\section{Introduction}

Facial aesthetics begin with the marriage of hard and soft tissue integration; however, it is the changing balance

\footnotetext{
*Corresponding author.
} 
of these elements that is the hallmark of the aging process [1]. The major forces responsible for facial aging include: gravity, soft tissue maturation, skeletal remodeling, muscular facial activity, and solar changes. Clearly, a person's age often is judged on the appearance of his or her skin. Although much has been written on cutaneous gerontology, it is really the balance of skeletal structure, soft tissue, and skin that is responsible for the appearance of cutaneous senescence [1] [2].

Wrinkles or facial lines may be divided into: coarse, medium and fine. Wrinkles are the most clinically apparent changes in the aging skin. Both intrinsically aged skin and extrinsically aged skin show wrinkling. As the skin ages, a redundancy of tissue develops as the collagen and elastin fibers in the dermis weaken and the subcutaneous fat atrophies. The muscular attachment to the skin remains during the aging process with excess skin overlying the facial muscles buckling, resulting in wrinkling [3] [4].

Human skin, like all organs, undergoes chronological aging. In addition, unlike other organs, skin is in direct contact with the environment and therefore undergoes aging as a consequence of environmental damage. The primary environmental factor that causes human skin aging is UV irradiation from the sun [5] [6]. Wrinkling of face is a common feature of aging and each individual could have his own characteristic picture of disease. This work is conducted to categorize the wrinkles of each individual in order to find the characteristic picture of each individual aiming to find so called a print of aging.

\section{Patients and Methods}

This is an observational study that had been carried out in Department of Dermatology-Baghdad Teaching Hospital, Baghdad, Iraq from April 2011 through April 2013. It included (1011) patients with their ages more than 30 years.

Each subject's face wrinkles were examined closely while the subject was sitting with facial muscles relaxed in a well-illuminated room. The forehead, glabella, periorbital, nasolabial, side of the face and perioral areas were examined closely.

Wrinkles of glabella and forehead were described as horizontal or vertical. The number of wrinkles from each was calculated and categorized as either one, two or more. Vertical wrinkles on glabella were divided into one vertical line, Triangular shape, palm-tree shape and Mercedes shape.

In this study, Modified Fitzpatrick Wrinkle Scale (MFWS) for the assessment of nasolabial folds were used (Figure 1). Wrinkle depth is based on physical measurement by Digital Vernier Caliper and mechanical pencil. The depth of the wrinkle was measured by mechanical pencil, then the length of emerging micro carbon from mechanical pencil was measured by Digital Vernier Caliper (Figure 2).

Color photographs for each patient were performed. Frontal, right and left views were taken using Sony-digital, high sensitivity, 16.1 megapixel camera with fixed illumination and distance. These photos to be evaluated

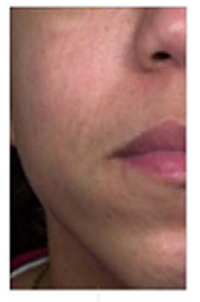

$$
\begin{gathered}
0 \\
\text { No } \\
\text { Wrinkle } \\
\text { No visible wrinkle } \\
\text { continuous skin } \\
\text { line }
\end{gathered}
$$$$
0.5
$$

Very shallow yet visible wrinkle
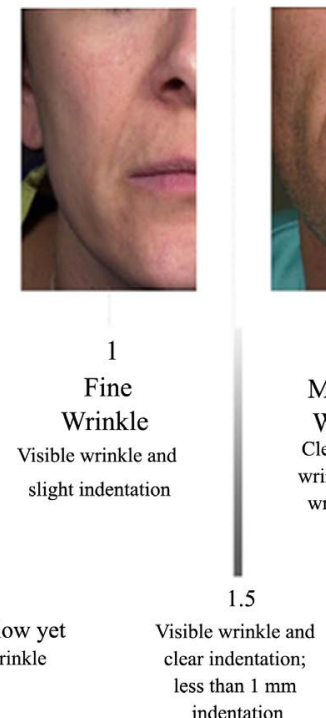

$$
\begin{aligned}
& \text { Visible wrinkle and } \\
& \text { clear indentation; } \\
& \text { less than } 1 \mathrm{~mm} \\
& \text { indentation }
\end{aligned}
$$

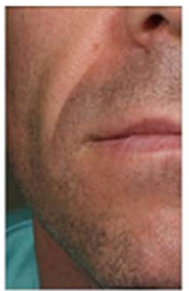

2

Moderate

Wrinkle

Clearly visible

wrinkle; $1-2 \mathrm{~mm}$

wrinkle depth
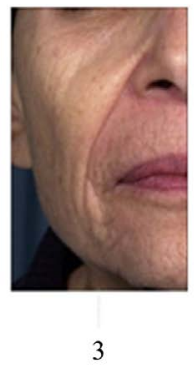

Deep

Wrinkle

Deeep and furrow

wrinkle; more

than $3 \mathrm{~mm}$

wrinkle depth
Figure 1. Reference photographs of the four main classes for MFWS. 


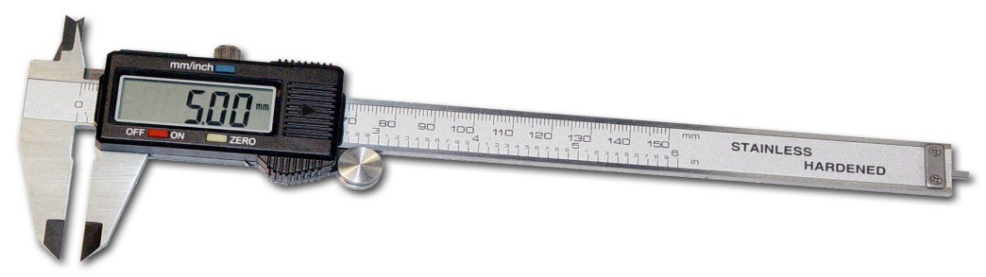

Figure 2. The Digital Vernier Caliper.

within each individual and to be compared with other cases in order to assess the morphology of wrinkle and other signs of face aging (sagging).

Formal consent was taken from each patient after full explanation about nature of present study and the goal of the present work. Also ethical approval was taken from the Scientific Council of Dermatology and Venereology-Iraqi Board for Medical Specializations.

Data were statistically described in terms of range, mean, standard deviation $( \pm S D)$, median, mode and frequencies (number of cases) and relative frequencies (percentages). Comparison between different groups in the present study was done using Chi square $\left(X^{2}\right)$ test. A probability value ( $\mathrm{P}$ value) less than 0.05 was considered significant. All statistical calculations were done using SPSS ver.20 (Statistical Package for the Social Science; SPSS Inc. Chicago, IL, USA).

\section{Results}

One thousand and eleven subjects were recruited in this study. Their age range from 30 - 86 years and mean \pm SD age was $51.47 \pm 17.32$ years. Most subjects (284; 28.2\%) were above 69 years, 679 subjects (67.2\%) were males and 332 (32.8\%) were females with male to female ratio equal to 2:1.

This study showed that glabella was affected by vertical and horizontal wrinkles. Vertical patterns were one line in 270 (26.7\%) subjects, triangular shape 265 (26.2\%), palm-tree shape 121 (12\%) and Mercedes shape in 42 (4.2\%) subjects. Horizontal patterns were one horizontal line in 482 (47.7\%), two lines in 205 (20.3\%) and more than two lines in 18 (1.8\%) subjects.

Forehead was also affected by vertical and horizontal lines. One vertical line was presented in 36 (3.6\%) subjects, two lines 24 (2.4\%) and more than two lines in 24 (2.4\%). One horizontal line was presented in 180 (17.8\%) subjects, two lines 300 (29.7\%) and more than two lines in 380 (37.6\%) (Table 1, Figure 3 and Figure 4).

Nasolabial folds were mildly affected 1n 174 (17.2\%), moderately affected 336 (33.2\%) and severely affected in 447 (44.2\%) subjects. More than 835 (82.6\%) of subjects had Crow's foot pattern in peri-orbital area while 50 (4.9\%) had Arboriform pattern. Perioral area was affected in 673 (66.6\%) of subjects and not affected in 338 (33.4\%) of subjects.

Glabella vertical and horizontal patters were significantly more in males than females (p value $<0.0001$ and $<$ 0.023 respectively) as well as forehead horizontal and vertical lines ( $\mathrm{p}$ value $<0.0001$ for both). Most affected males had glabellar T shape (28.4\%), one glabellar horizontal line (48.5\%) and more than two forehead horizontal lines (39.9\%). (Table 2)

Also the males were significantly more affected by periorbital and nasolabial folds ( $\mathrm{p}$ value $<0.0001$ for both). Most of them had crow's feet pattern (46.1\%) and severely affected nasolabial folds (35.8\%). There was significant difference between male and female regarding perioral involvement (p value 0.043) (Table 2).

\section{Discussion}

Aging is a normal natural process that affects every human being. There are many exacerbating factors that provoke the natural process like sun light exposure, smoking and plus others [1] [7]. This aging process affects every structure of the face including epidermis, dermis, fatty layer, underlying muscles and bones [1] [8] but these structures are not affected in equal amount and in parallel way as some individual might have the aging 


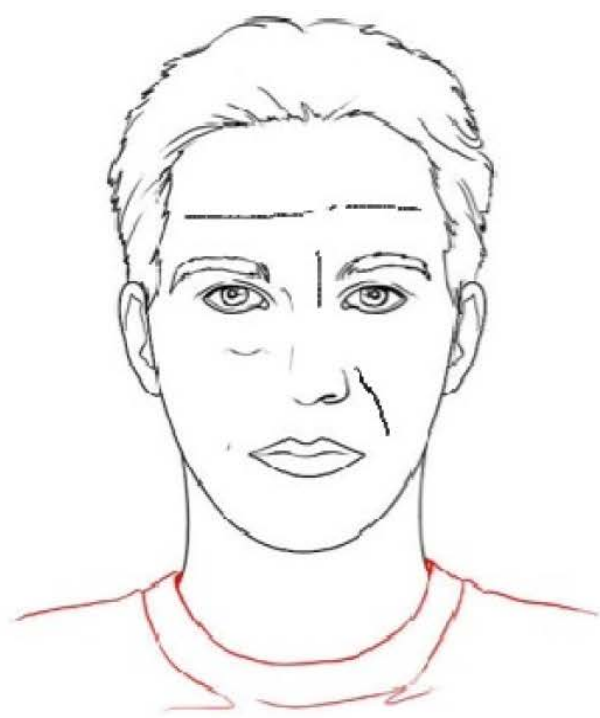

(a) One worry line, one frown line and nasolabial fold

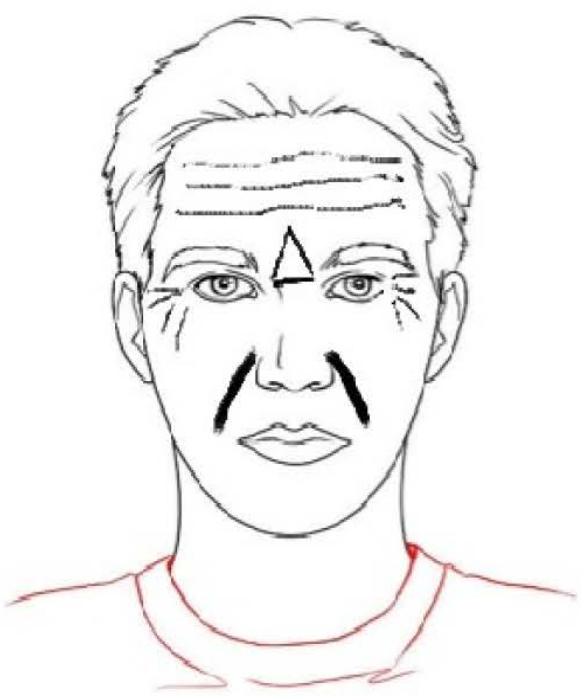

(c) >two worry lines, triangular shape, crow's feet and deep nasolabial folds

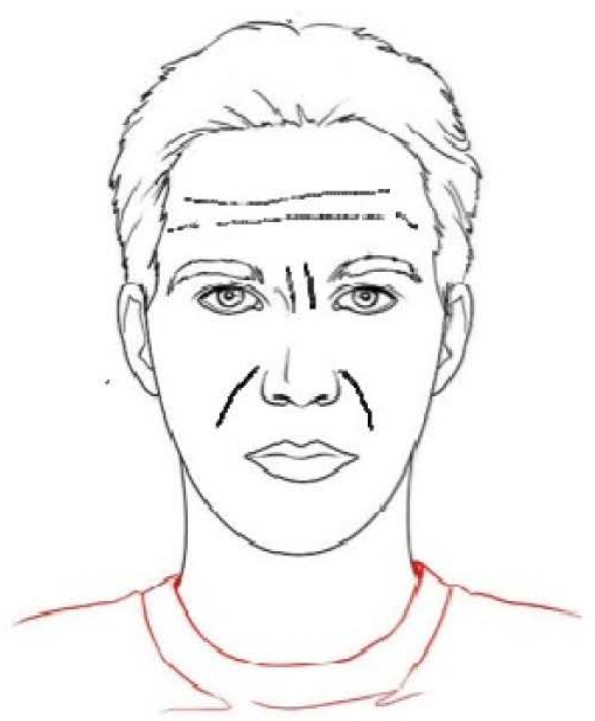

(b) Two worry line, two frown lines

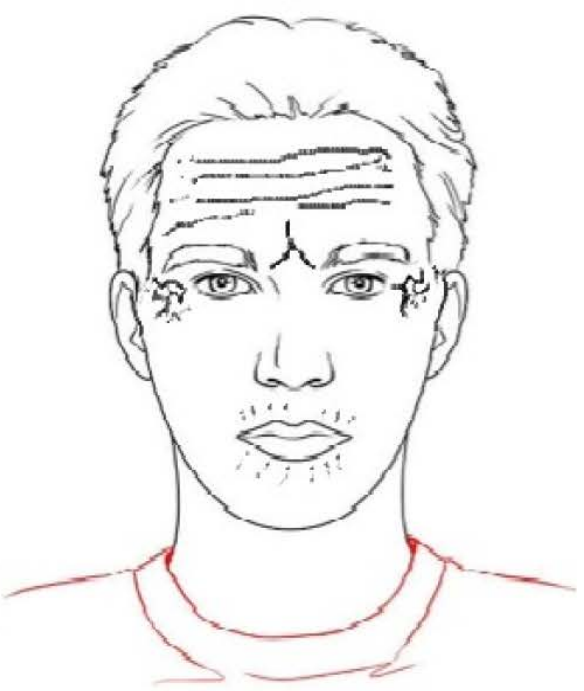

(d) $>$ two worry lines, Mercedes shape, arboriform and perioral wrinkles.

\section{Figure 3. Schematic draws of horizontal wrinkle patterns.}

process affecting mainly the epidermis and dermis and appear as wrinkling [9] while other might have involvement of fatty layer, fatty lobules of the face that end with sagging of skin rather than wrinkling [10]. While in some people all structures might be affected including the bone and might appear as mom mated individual. [11].

Wrinkling is an important feature and marker of aging that could be also variable among people. The wrinkling could be fine or coarse and could affect one region more than the other [4] [12]. So according to regional variation, each individual might have his own wrinkles giving him or her characteristic morphological picture that could simulate a print. These patterns of wrinkling unfortunately are not well studied in the medical literature although the aging process is a very well-studied and evaluated. Hence, the present work is to best of our knowledge is the first study that dealt with morphology of the wrinkles rather than with descriptive terms of the cause of the wrinkles. The previous literatures described wrinkles depending entirely on the action of facial muscles 
that produced the wrinkles. The present study described morphological criteria for evaluation of wrinkles particularly upper half of the face.

In present study, we noticed many patterns of wrinkling in each region of face which are not described in details in the previous literatures. The previous studies mentioned the worry lines as forehead wrinkles while our study found many patterns. In forehead, the wrinkles can be classified according to orientation of lines to vertical and horizontal lines. Vertical and horizontal lines were one line, two lines and more than two lines.

Also, previous literatures noted frown lines on glabella, while this study revealed many wrinkle's pattern. In glabella, the wrinkle patterns can be divided to vertical, horizontal lines or both. Vertical patterns were classified according to line patterns to one line, triangular shape, palm-tree shape and Mercedes shape. Horizontal patterns were classified into one line, two lines and more than two lines.

This study showed same patterns which were mentioned in previous literatures like crow's foot which was found in peri-orbital areas and nasolabial fold grades which might be not affected at all, mildly affected, moderately af-

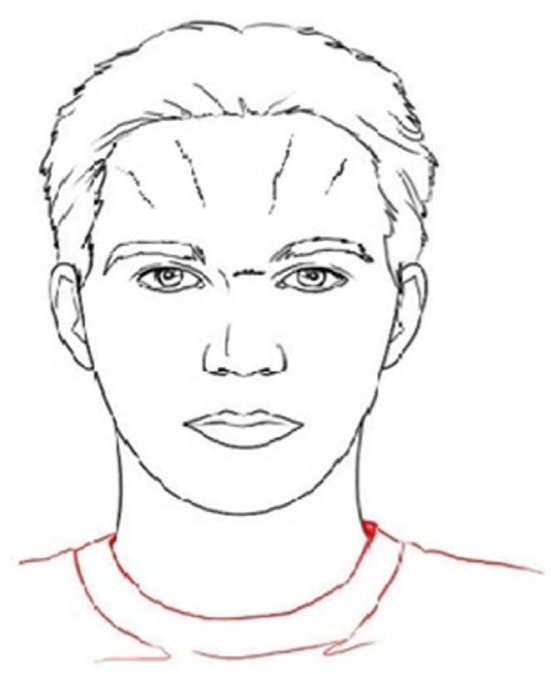

(a) $>$ Two vertical forehead lines and one horizontal (glabella)

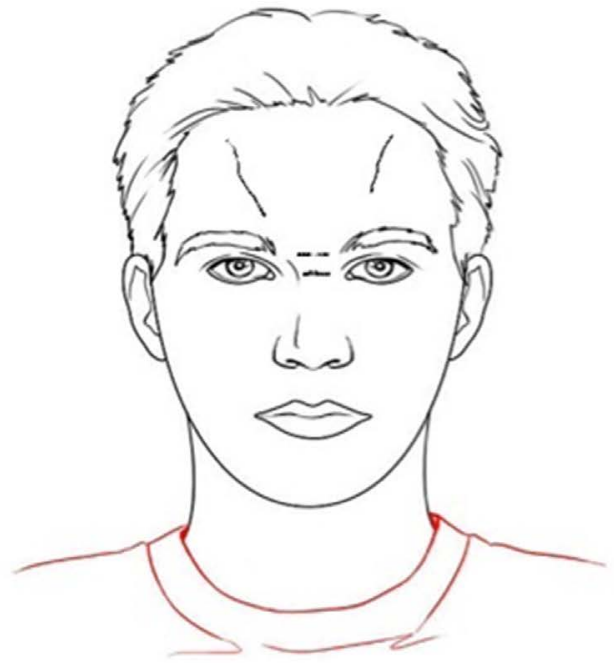

(b) $>$ Two vertical forehead lines and two horizontal lines (glabella).

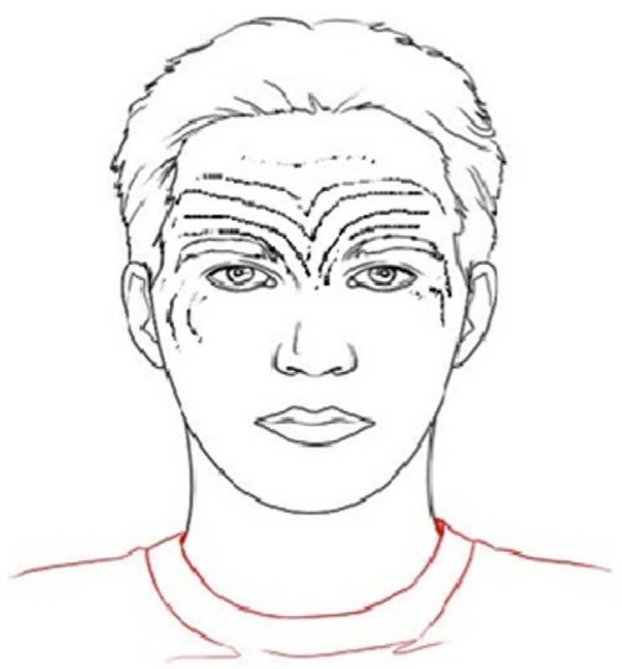

(c) Tree shape wrinkles

Figure 4. Schematic draws of vertical wrinkle patterns. 
Table 1. Frequency of observed wrinkles according to site.

\begin{tabular}{|c|c|c|c|}
\hline & & N (1011) & (\%) \\
\hline \multirow{5}{*}{ Glabella vertical patterns } & - Absent & 313 & 31.0 \\
\hline & - $\quad$ One line (frown line) & 270 & 26.7 \\
\hline & - Triangular shape & 265 & 26.2 \\
\hline & - Palm-Tree shape & 121 & 12.0 \\
\hline & - Mercedes shape & 42 & 4.2 \\
\hline \multirow{7}{*}{ Glabella horizontal patterns } & Total & 1011 & 100.0 \\
\hline & - $\quad$ Not affected & 306 & 30.3 \\
\hline & - One line & 482 & 47.7 \\
\hline & - Two lines & 205 & 20.3 \\
\hline & - $>$ two lines & 18 & 1.8 \\
\hline & Total & 1011 & 100.0 \\
\hline & - Not affected & 927 & 91.7 \\
\hline \multirow{3}{*}{ Forehead vertical patterns } & - One line & 36 & 3.6 \\
\hline & - Two lines & 24 & 2.4 \\
\hline & - >two lines & 24 & 2.4 \\
\hline \multirow{6}{*}{ Forehead horizontal patterns } & Total & 1011 & 100.0 \\
\hline & - $\quad$ Not affected & 151 & 14.9 \\
\hline & - $\quad$ One line (worry line) & 180 & 17.8 \\
\hline & - Two lines (worry lines) & 300 & 29.7 \\
\hline & - $\quad$ >two lines (worry lines) & 380 & 37.6 \\
\hline & Total & 1011 & 100.0 \\
\hline \multirow{5}{*}{ Nasolabial } & - Not present & 54 & 5.3 \\
\hline & - Mildly affected & 174 & 17.2 \\
\hline & - Moderate & 336 & 33.2 \\
\hline & - Sever affected & 447 & 44.2 \\
\hline & Total & 1011 & 100.0 \\
\hline \multirow{4}{*}{ Periorbital } & - Absent & 126 & 12.5 \\
\hline & - Crow's feet & 835 & 82.6 \\
\hline & - Arboriform & 50 & 4.9 \\
\hline & Total & 1011 & 100.0 \\
\hline \multirow{3}{*}{ Perioral area } & - Not affected & 673 & 66.6 \\
\hline & - Affected & 338 & 33.4 \\
\hline & Total & 1011 & 100.0 \\
\hline
\end{tabular}

fected or severely affected [13].

Men showed increased forehead and glabellar wrinkles compared with women. In contrast, gender-dependent differences were found in perioral wrinkles as women were affected more than men significantly. Other facial 
Table 2. Frequency of observed wrinkles according to gender.

\begin{tabular}{|c|c|c|c|c|c|}
\hline & & $\begin{array}{c}\text { Male } \\
\text { N (\%) }\end{array}$ & $\begin{array}{c}\text { Female } \\
\mathrm{N}(\%)\end{array}$ & $\begin{array}{l}\text { Total } \\
\text { N (\%) }\end{array}$ & $\mathrm{P}$ value \\
\hline \multirow{5}{*}{ Glabella vertical pattern } & - One line & $198(28.4 \%)$ & $72(10.3 \%)$ & $270(38.7)$ & \multirow{5}{*}{0.0001} \\
\hline & - Triangular shape & $162(23.2 \%)$ & $103(14.8 \%)$ & $265(38.0)$ & \\
\hline & - Tree shape & $96(13.8 \%)$ & $25(3.6 \%)$ & $121(17.3)$ & \\
\hline & - Mercedes shape & $24(3.4 \%)$ & $18(2.6 \%)$ & $42(6.0)$ & \\
\hline & Total & $480(68.8 \%)$ & $218(31.2 \%)$ & $698(100 \%)$ & \\
\hline \multirow{4}{*}{ Horizontal line } & - 1 line & $342(48.5 \%)$ & 140 (19.9\%) & 482 (68.4\%) & \multirow{4}{*}{0.023} \\
\hline & - 2 lines & 151 (21.4\%) & 54 (7.7\%) & 205 (29.1\%) & \\
\hline & - $\quad>2$ lines & $18(2.6 \%)$ & $0(0)$ & $18(2.6 \%)$ & \\
\hline & Total & $511(72.5 \%)$ & $194(27.5 \%)$ & 705 (100\%) & \\
\hline \multirow{4}{*}{ Forehead horizontal pattern } & - 1 line & $108(12.6 \%)$ & $72(8.4 \%)$ & 180 (20.9\%) & \multirow{4}{*}{0.0001} \\
\hline & - 2 lines & $222(25.8 \%)$ & 78 (9.1\%) & 300 (34.9\%) & \\
\hline & - $\quad>2$ lines & $343(39.9 \%)$ & $37(4.3 \%)$ & 380 (44.2\%) & \\
\hline & Total & $673(78.3 \%)$ & $187(21.7 \%)$ & $860(100 \%)$ & \\
\hline \multirow{4}{*}{ Forehead vertical pattern } & - 1 line & $24(28.6 \%)$ & $12(14.3 \%)$ & $36(42.9 \%)$ & \multirow{4}{*}{0.0001} \\
\hline & - 2 lines & 24 (28.6\%) & $0(0.0 \%)$ & $24(28.6 \%)$ & \\
\hline & - $\quad>2$ lines & $24(28.6 \%)$ & $0(0.0 \%)$ & $24(28.6 \%)$ & \\
\hline & Total & $72(85.7 \%)$ & $12(14.3 \%)$ & $84(100.0 \%)$ & \\
\hline \multirow{3}{*}{ Periorbital } & - Crows foot & $601(67.9 \%)$ & 234 (26.5\%) & 835 (94.4\%) & \multirow{3}{*}{0.0001} \\
\hline & - Arboriform & $42(4.7 \%)$ & $8(0.9 \%)$ & $50(5.6 \%)$ & \\
\hline & Total & $643(72.7 \%)$ & $242(27.3 \%)$ & 885 (100\%) & \\
\hline \multirow{4}{*}{ Nasolabial } & - Mildly affected & $96(10.0 \%)$ & $78(8.2 \%)$ & $174(18.2 \%)$ & \multirow{4}{*}{0.0001} \\
\hline & - Moderate & 210 (21.9\%) & $126(13.2 \%)$ & 336 (35.1\%) & \\
\hline & - Severe & $343(35.8 \%)$ & 104 (10.9\%) & 447 (46.7\%) & \\
\hline & Total & $649(67.8 \%)$ & 308 (32.2\%) & 957 (100.0\%) & \\
\hline Perioral & - Affected & $108(32 \%)$ & 230 (68\%) & $338(100 \%)$ & 0.043 \\
\hline
\end{tabular}

wrinkles were greater in men than in women in like periorbital, side of the face and nasolabial folds [13]-[15]. All these results were agreed with Tsukahara et al. except for perioral wrinkles in which wrinkles in women were equal to those in men [15].

The study agreed with Emma et al. [14] that all of the following could be contributing factors to the presence of more and deeper perioral wrinkles in women:

- Women's perioral skin contains fewer sweat glands and sebaceous glands which could influence the natural filling of the skin.

- Women's perioral skin contains fewer blood vessels and, therefore, is less vascularized compared to men, which could accelerate the development of wrinkles.

- In women, the closer attachment of the muscular fibers surrounding the orifice of the mouth to the dermis may cause an inward traction, thereby creating deeper wrinkles. In conclusion each individual or groups of individual has characteristic morphological pattern that might deserve the name of a print.

\section{Disclosure}

This study is an independent study and not funded by any of drug company. 


\section{References}

[1] Rabe, J.H., Mamelak, A.J., McElgunn, P.J., Morison, W.L. and Sauder, D.N. (2006) Photoaging: Mechanisms and Repair. Journal of the American Academy of Dermatology, 55, 1-19. http://dx.doi.org/10.1016/j.jaad.2005.05.010

[2] Hiatt, J.L. and Gartner, L.P. (2009) Textbook of Head \& Neck Anatomy. 4th Edition, Lippincott Williams and Wilkins, Philadelphia, 31-39.

[3] Fisher, G.J., Kang, S. and Varani, J. (2002) Mechanisms of Photoaging and Chronological Skin Aging. Archives Dermatology, 138, 1462-1470. http://dx.doi.org/10.1001/archderm.138.11.1462

[4] Prystowsky, J.H. and Siegel, D.M. (1999) Anatomy of Facial Lines and Wrinkles. In: Blitzer, A., Binder, W.J., Bayed, J.B. and Carruthers, A., Eds., Management of Facial Lines and Wrinkles, 2nd Edition, Lippincott Williams and Wilkins Publication, Philadelphia, 1-3.

[5] Ghersetich, I., Troiano, M., De Giorgi, V. and Lotti, T. (2007) Receptors in Skin Ageing and Antiageing Agents. Dermatologic Clinics, 25, 655-662. http://dx.doi.org/10.1016/j.det.2007.06.018

[6] Sharquie, K.E., Al-Rawi, J.R. and Al-Amily, B.D. (2004) Aging Changes around Auricles. Iraqi Journal of Community Medicine, 17, 224-229.

[7] Scharffetter-Kochanek, K., Brenneisen, P. and Wenk, J. (2000) Photoaging of the Skin: From Phenotype to Mechanisms. Experimental Gerontology, 35, 307-316. http://dx.doi.org/10.1016/s0531-5565(00)00098-x

[8] Bhawan, J., Andersen, W. and Lee, J. (1995) Photoaging versus Intrinsic Aging: A Morphologic Assessment of Facial Skin. Journal of Cutaneous Pathology, 22, 154. http://dx.doi.org/10.1111/j.1600-0560.1995.tb01399.x

[9] Nguyen, H.T., Isaacowitz, D.M. and Rubin, P.A. (2009) Age and Fatigue-Related Markers of Human Faces: An EyeTracking Study. Ophthalmology, 116, 355-360. http://dx.doi.org/10.1016/j.ophtha.2008.10.007

[10] Marquardt, S.R. and Stephen, R. (2002) Marquardt on the Golden Decagon and Human Facial Beauty. Interview by Dr. Gottlieb. Journal of Clinical Orthodontics, 36, 339-347.

[11] Oldenburg, M., Kuechmeister, B., Ohnemus, U., Baur, X. and Moll, I. (2013) Extrinsic Skin Ageing Symptoms in Seafarers Subject to High Work-Related Exposure to UV Radiation. European Journal of Dermatology, 12, 112-114.

[12] Boissieux, L., Kiss, G., Thalmann, N.M. and Kalra, P. (2000) Simulation of Skin Aging and Wrinkles with Cosmetics Insight. Eurographics 2000, 15-27. http://dx.doi.org/10.1007/978-3-7091-6344-3_2

[13] Shoshani, D., Markovitz, E., Onstrey, S.J.M. and Narins, D.J. (2008) Measurement Tool for Nasolabial Wrinkle Severity Assessment. Dermatologic Surgery, 34, 85-91.

[14] Paes, E.C., Teepen, H.J.L.J.M., Koop, W.A. and Kon, M. (2009) Perioral Wrinkles: Histologic Differences between Men and Women. Aesthetic Surgery Journal November, 29, 467-472. http://dx.doi.org/10.1016/j.asj.2009.08.018

[15] Tsukahara, K., Hotta, M., Osanai, O., Kawada, H., Kitahara, T. and Takema, Y. (2013) Gender-Dependent Differences in Degree of Facial Wrinkles. Skin Research and Technology, 19, 65-71. http://dx.doi.org/10.1111/j.1600-0846.2011.00609.x 